\title{
IMMUNISING PLANTS - DEVELOPING ANTIBODY FRAGMENTS AGAINST A POTYVIRUS REPLICATION PROTEIN
}

\author{
D. WEBSTER ${ }^{1}$, P. GUY ${ }^{1}$ and R. FORSTER ${ }^{2}$ \\ ${ }^{1}$ Department of Botany, University of Otago, PO Box 56, Dunedin \\ ${ }^{2}$ HortResearch, Private Bag 92169, Auckland
}

Few resistance mechanisms are available that combat a broad spectrum of potyviruses. We propose to produce single chain antibody fragments that bind to the potyvirus cylindrical inclusion (CI) protein. The potyvirus CI protein is a helicase protein that is assumed to unwind dsRNA during virus replication. Our aim is to find a single chain antibody fragment that is able to bind to a highly conserved helicase motif, such as the NTP binding domain. Such an antibody fragment has the potential to confer resistance to a broad spectrum of potyviruses. A library of single chain antibody fragments has been assembled from BALB/c mice immunised with purified $\mathrm{CI}$ protein and cloned into the phagemid vector $\mathrm{pHEN}$. The resulting combinatorial library was of adequate size and diversity, containing an acceptable proportion of full size single chain antibody fragments. The library is currently being screened for CIspecific single chain antibody fragments by phage display.

\section{ISOLATION AND CULTURE OF CIBORINIA CAMELLIAE}

\author{
C. TAYLOR and P. LONG \\ Institute of Natural Resources, Massey University, \\ Palmerston North
}

Ciborinia camelliae (the fungal causal agent of camellia flower blight) was first discovered in New Zealand in 1993 and has now spread across the lower half of the North Island. There is surprisingly little information on the pathogen or the disease in the scientific literature and this work was initiated after preliminary attempts to isolate the fungus from ascospores were unsuccessful. Successful culturing from field collected sclerotia required a rigorous isolation procedure. Overseas literature indicated that the fungus grew well on potato dextrose agar (PDA) but approximately $50 \%$ of isolations and subcultures failed to grow or did not grow well on Merck PDA. A comparison of agar media showed that the pathogen grew well on new DIFCO PDA, new Oxoid PDA and new Oxoid malt extract agar (MEA) but grew poorly on new Merck PDA, an old batch of Oxoid PDA and homemade PDA. Optimum temperature for growth on agar was $15-20^{\circ} \mathrm{C}$ but some isolates grew better than others. Sclerotial formation could be detected after 8 days growth and microconidia were formed after 10 days. 